Instituto Internacional de Investigación y Desarrollo Tecnológico Educativo INDTEC, C.A.

DOI: https://doi.org/10.29394/scientific.issn.2542-2987.2017.2.3.9.176-189

OAI-PMH: http://www.indteca.com/ojs/index.php/Revista Scientific/oai

\title{
Plan Educativo para la Producción de Abono Orgánico Mediante Microorganismos Eficientes
}

\author{
Autora: Diana Carolina Cuevas Ordoñez \\ Universidad Pedagógica Experimental Libertador, UPEL \\ dianacarolinacuevas1985@gmail.com \\ Barinas, Venezuela
}

\section{Resumen}

La presente investigación tiene como propósito desarrollar un Plan Educativo para la Producción de Abono Orgánico mediante Microorganismos Eficientes dirigido a los docentes de la Escuela Nacional Bolivariana "José Vicente Unda" de la Parroquia Barinitas, Municipio Bolívar, Estado Barinas. La naturaleza de la investigación se enmarcada en la metodología cualitativa, bajo la modalidad de una investigación acción participativa, con un diseño de campo, bajo las siguientes fases: diagnóstico, planificación, ejecución y evaluación, apoyada con una entrevista a profundidad, aplicando un registro audiovisual cara a cara y guiones a través de preguntas generadoras, para responder dicha entrevista se contará con tres informantes claves. En cuanto a la técnica de análisis de información se elaborará el cuadro de categorías con el fin de poder realizar comparaciones y posibles contrastes. Entre las consideraciones finales se estima que la creación de actividades prácticas para la producción de abono orgánico mediante microorganismos eficientes representa un aporte de suma importancia para el fortalecimiento de los espacios socioproductivos en la institución, manteniendo la biodiversidad y disminuyendo el impacto negativo al ambiente.

Palabras clave: plan educativo; abono orgánico; microorganismos eficientes. 


\title{
Training Program Organic Fertilizer Production by Microorganisms Efficient
}

\begin{abstract}
This research aims to develop a training program for Organic Fertilizer Production by Efficient Microorganisms aimed at teachers of the Bolivarian National School "Jose Vicente Unda" Barinitas Parish, Municipality Bolivar, Barinas State, 2015-2016 school year. The nature of research is framed in qualitative methodology, in the form of participatory action research, with a field design under the following phases: diagnosis, planning, implementation and evaluation, supported by a depth interview, using a log audiovisual face to face and through generating scripts questions, you will have three key informants. As for the technical analysis of the information box categories in order to make comparisons and draw contrasts possible. Among the final considerations it is estimated that the creation of practical activities for the production of organic fertilizer through efficient microorganisms represents an important contribution to strengthening the socio spaces in the institution, maintaining biodiversity and reducing the negative impact to the environment.
\end{abstract}

Keywords: educational plan; organic fertilizer; efficient microorganisms. 


\section{Introducción}

La tecnología de Microorganismos Eficientes (EM) son todos aquellos nutrientes obtenidos de los ecosistemas naturales y seleccionados por sus efectos positivos en los cultivos; los mismos se desarrolló a través de una mescla de microorganismos para mejorar la productividad de los sistemas de producción orgánica. Así lo define Piedrabuena (2003) como:

Un grupo de especies microbianas cuya presencia en el suelo, mejoran su fertilidad, física, química, biológica, y resistencia a los patógenos, entre otras. Hablamos de varios tipos de organismos distintos, no de uno solo. Sin embargo, una cuestión es que el ecosistema del suelo albergue tales microorganismos, otra, poder "potenciar" su presencia y finalmente otra muy distinta inocularla a partir de productos comerciales (pág. 74).

En efecto, los microorganismos eficientes se encuentran principalmente en los ecosistemas de los suelos donde recoge todos los nutrientes que este posee; estos son resistentes a los patógenos y se pueden clasificar en varios tipos según sus características.

En este sentido, los suelos pueden atesorar gran variedad de comunidades microbianas muy dispares, aunque ricas en microorganismos eficientes. Cuando a causa de la contaminación u otro impacto ambiental, el medio edáfico se degrada, lo hace frecuentemente porque tal perturbación ha descompensado en normal funcionamiento del metabolismo del suelo. Reconocido el problema se puede intentar corregir por diversos medios; No obstante, debemos enfatizar que no existen ensamblajes milagrosos cuya crianza en laboratorios y posterior inoculación en el campo resuelva el mal de una vez por todas.

En este orden de ideas, en algunos países de Suramérica se está iniciando un periodo de adaptación en materia de utilización de los microorganismos eficiente, ya que dichos suelos y la salud de los trabajadores 
de la agricultura se han venido deteriorando con las constantes utilizaciones de agroquímicos. De esta manera es visto por Monasterio (2008), quien manifiesta que:

En Suramérica actualmente las medidas utilizadas para el control de las enfermedades del suelo son el uso de productos químicos; sin embargo, su uso indiscriminado ha tenido grandes consecuencias y se han encontrado aislamientos de hongos resistentes a fungicidas. También hay evidencias importantes de una grave contaminación derivada de los plaguicidas, que no sólo afecta a la flora y la fauna que han sido expuestas en forma significativa a dichas sustancias, sino también han contribuido al deterioro de la calidad del aire, agua, suelos y alimentos, así como también de la salud de jornaleros y consumidores (pág. 140).

De hecho, en esta región la mayoría de las acciones tomadas para controlar las malezas e impurezas de los suelos productivos están direccionadas al uso de productos agroquímicos, trayendo como consecuencia como la contaminación ambiental y se han producido muchos focos de problemas de salud en los productores y trabajadores de la agricultura.

En Venezuela el Instituto Nacional de Salud Agrícola Integral (INSAI), ha determinado que el uso de agentes químicos en el control de hongos, bacterias en los suelos productivos utilizados para la agricultura, han ocasionado efectos carcinógenos, teratogénicos, alta residualidad, período largo de degradación, contaminación ambiental y otros efectos negativos; Así como a la resistencia de los microorganismos patógenos a estos productos sintético, tal como lo expresa Martínez (1999), quien dijo que:

El uso de productos químicos en Venezuela está generando grandes pérdidas de la cubierta vegetal, la erosión de los suelos, incremento de salinidad de los suelos, disminución considerable de los mantos freáticos, la perdida de diversidad agrícola y genética, la contaminación del aire, son algunas de 
las múltiples consecuencias de la agricultura basada en agroquímicos (pág. 85).

En otras palabras, el uso de los agroquímicos ha generado algunos factores en las condiciones ambientales, enfermedades tanto de los suelos como de las personas que lo manipulan, causa aislamientos de hongos resistentes a fungicidas afectando la flora y rubros ocasionando una vegetación mal sana.

En este contexto, los múltiples factores negativos ocasionados por los usos de agroquímicos, están relacionados con los altos índices de contaminación de los suelos agrícolas, la perdida de los nutrientes y vitaminas de los suelos, la contaminación de las aguas y atmosfera; unido a estos los altos precios y la escasez de los productos agroquímicos, ha generado la necesidad de buscar alternativas agroecológicas que minimicen el uso de productos químicos para solucionar los problemas de conservación y preservación de los suelos agrícolas. En tal sentido, Rodríguez (2010), especificó que:

El uso de la agricultura ecológica, puede ser altamente productiva y a su vez sostenible en producción y conservación a largo plazo con la finalidad de poder solventar el abastecimiento de alimentos a una creciente población humana. Con un enfoque de la agricultura más ligado al medioambiente y más sensible socialmente; centrado no sólo en la producción sino también en la sostenibilidad ecológica del sistema de producción (pág. 45).

De hecho, la utilización de abono natural puede ser altamente productiva tanto para el mantenimiento sostenible de los suelos y del medio ambiente, como para la elevación de la producción agrícola y en fin, para la obtención de producto de alta calidad y ecológicamente comestibles.

El estado Barinas, específicamente en el Municipio Bolívar se encuentra ubicada la Escuela Nacional Bolivariana "José Vicente Unda" (ENBJVU), la 
cual no escapa de esta realidad y donde se han estado llevando a cabo las actividades de siembra y cultivo de hortalizas en huertos escolares sin ningún tipo de nutrientes y vitaminas que ayuden a las plantas a completar su desarrollo de forma eficiente. Trayendo como consecuencia que los huertos escolares elaborados en dicha institución, se les mueran las plantas y por ende tengan una pérdida total o parcial de la cosecha.

No obstante, en observaciones directas realizadas en la presente investigación, se ha evidenciado como pocos docentes y estudiantes se involucran o capacitan en el conocimiento de este tipo de programas para el abordaje de los aspectos ambientales de sostenibilidad y aprovechamiento de los recursos con que cuenta la institución educativa. De allí que se propone un plan educativo para la producción de abono orgánico mediante el abordaje de los Microorganismos Eficientes dirigido a los docentes de la Unidad Nacional Bolivariana José Vicente Unda.

\subsection{En función de lo antes expuesto surgen las siguientes interrogantes:}

¿Cuáles son los conocimientos que poseen los docentes de la Unidad educativa José Vicente Unda, en la producción de abono orgánico mediante el abordaje de microorganismos eficientes?

¿Cómo deben diseñarse el plan educativo dirigido a los docentes de la Unidad educativa José Vicente Unda, en la producción de abono orgánico mediante el abordaje de microorganismos eficientes?

¿Cómo sería la ejecución del plan educativo dirigido a los docentes de la Unidad educativa José Vicente Unda, en la producción de abono orgánico mediante el abordaje de microorganismos eficientes?

¿Cómo evaluar el impacto del plan educativo dirigido a los docentes de la Unidad educativa José Vicente Unda, en la producción de abono orgánico mediante el abordaje de microorganismos eficientes? 


\section{Microorganismos eficientes.}

Piedrabuena (2003), indica que: los Microorganismos eficientes son:

Una combinación de microorganismos beneficiosos de cuatro géneros principales: Bacterias fototróficas, levaduras, bacterias productoras de ácido láctico y hongos de fermentación. Estos microorganismos efectivos cuando entran en contacto con materia orgánica secretan substancias beneficiosas como vitaminas, ácidos orgánicos, minerales quelatados y fundamentalmente substancias antioxidantes. Además, mediante su acción cambian la micro y macro flora de los suelos y mejoran el equilibrio natural, de manera que los suelos causantes de enfermedades se conviertan en suelos supresores de enfermedades, y ésta se transforme a su vez en tierra (suelo) azimogénico. A través de los efectos antioxidantes promueven la descomposición de la materia orgánica y aumentan el contenido de humus (pág. 53).

En la definición que postula este autor se entiende claramente que los Microorganismos Eficientes en este caso están compuestos por 4 tipos de organismos que ayudan a cambiar la flora de los suelos y mejorar su equilibrio natural.

De la misma manera para Hurtado (2001), expresa que:

EI EM viene únicamente en forma líquida y contiene microorganismos útiles y seguros. No es un fertilizante, ni un químico, no es sintético y no ha sido modificado genéticamente. Este se utiliza junto con la materia orgánica para enriquecer los suelos y para mejorar la flora y la labranza. Dichos microorganismos se encuentran en estado latente y por lo tanto se utiliza para hacer otros productos secundarios de microorganismos eficientes (pág. 62).

De acuerdo a lo planteado por este autor los Microorganismos Eficientes vienen en forma líquida, no es un químico pues es elaborado con materia orgánica y se utiliza para mejorar el estado de los suelos y los cultivos entre otros, ya que cuenta con múltiples de beneficios. 


\subsection{Tipos de organismos presentes en los microorganismos eficientes.}

\subsubsection{Bacterias Ácido Lácticas}

Biosca (2001), manifiesta que estas bacterias producen ácido láctico a partir de azúcares y otros carbohidratos sintetizados por bacterias fototróficas y levaduras. El ácido láctico es un fuerte esterilizador, suprime microorganismos patógenos e incrementa la rápida descomposición de materia orgánica. Las bacterias ácido lácticas aumentan la fragmentación de los componentes de la materia orgánica, como la lignina y la celulosa, transformando esos materiales sin causar influencias negativas en el proceso. Ayuda a solubilizar la cal y el fosfato de roca.

\subsubsection{Bacterias Fotosintéticas}

Biosca (2001: 13), indica que son "bacterias autótrofas que sintetizan sustancias útiles a partir de secreciones de raíces, materia orgánica y gases dañinos, usando la luz solar y el calor del suelo como fuente de energía". Las sustancias sintetizadas comprenden aminoácidos, ácidos nucleicos, sustancias bioactivas y azúcares, promoviendo el crecimiento y desarrollo de las plantas. Los metabolitos son absorbidos directamente por ellas, y actúan como sustrato para incrementar la población de otros microorganismos eficientes. EARTH (2008: 67), expresa que "estas bacterias funcionan como un componente importante del EM. Ayudan a mantener el balance con otros microorganismos benéficos, permitiendo a coexistir y funcionar juntamente con los mismos".

\subsubsection{Levaduras}

Biosca (2001), indica que estos:

Microorganismos sintetizan sustancias antimicrobiales y útiles para el crecimiento de las plantas a partir de aminoácidos y azúcares secretados por bacterias fototróficas, materia orgánica y raíces de las plantas. Las sustancias bioactivas, 
como hormonas y enzimas, producidas por las levaduras, promueven la división celular activa (pág. 32).

En efecto, las secreciones son sustratos útiles para microorganismos eficientes como bacterias ácido lácticas y actinomiceto; las misma, manifiesta que la levadura ayuda a fermentar la materia orgánica y contiene vitaminas y aminoácidos.

\subsubsection{Actinomicetos}

APNAN (2003): manifiesta que funcionan como antagonistas de muchas bacterias y hongos patógenos de las plantas debido a que producen antibióticos (efectos biostáticos y biácidas). Benefician el crecimiento y actividad del Azotobacter y de las micorrizas.

\subsection{Abono Orgánico.}

El abono orgánico según Gómez (2000: 24), lo define como: "un recurso capaz de proporcionar al suelo o las plantas cantidades notables de nutrientes esenciales, principalmente nitrógeno, fósforo y potasio", una fortaleza del abono orgánico es que tiene todos los elementos esenciales en los niveles apropiados de materia orgánica, haciendo de él, un componente natural y necesario para elevar la calidad de la producción de la siembra.

\subsection{Uso del Abono Orgánico}

El abono orgánico representa una alternativa ecológica que se puede utilizar tanto en grandes plantaciones como en pequeños huertos; puesto que este agrega substrato aun medio que sirve de soporte físico a la planta y además, le proporciona nutrientes y agua para el desarrollo de la misma. 


\subsection{Tipos de Abonos Orgánicos}

Según Zérega (1993), dentro de los abonos orgánicos más utilizados en la actualidad se encuentran:

El humus de lombriz, el bocashi, el compost, la pulpa de café entre otros, en los cuales la materia prima para su elaboración suele ser desechos del beneficio del café, vegetales entre otros, que son transformados y pueden ser una fuente importante de nutrientes para la agricultura orgánica (pág. 65).

En tal sentido, el proceso que conlleva a cabo la producción de abono es la composición en grandes cantidades de fósforo y micronutrientes como en zinc, boro, entre otros, produciendo una mineralización de la materia orgánica como los residuos de cultivo, estiércol y compost.

\subsection{Plan}

Según Gómez (2012): es una intención o un proyecto, se trata de un modelo sistemático que se elabora antes de realizar una acción, el objetivo principal se dirigiría a encauzarla; En fin, es un escrito que precisa los detalles necesarios para realizar una actividad. Es decir, el plan puede ser el conjunto de decisiones explicitas y coherentes para asignar recursos a propósitos determinados.

\subsection{Plan Acción}

Para Rodríguez (2010), el Plan Acción es:

Una herramienta de planificación empleada para la gestión y control de tareas o proyectos. Como tal, funciona como una hoja de ruta que establece la manera en que organizara, orientara e implementara el conjunto de tares necesarias para la consecución de objetivos y metas planteadas (pág. 23).

Es decir, el plan propone una forma de alcanzar los objetivos estratégicos que ya fueron previamente establecidos, suponiendo el paso 
previo a la ejecución de una idea; de la misma forma, estos planes no solo deben incluir cosas que quieren hacerse y como; también deben considerar las restricciones, las consecuencias de las acciones y las futuras revisiones que puedan ser necesarias.

\section{Metodología}

La presente investigación está sustentada metodológicamente en el enfoque cualitativo ya que la misma consiste en descripciones detalladas de situaciones, eventos, personas, interacciones y comportamientos que son observables. Por consiguiente, este método busca menos la generalización y se acerca más a la dialéctica y al interaccionismo simbólico. Una característica estratégica importante para este trabajo, ya que sienta bases para el método de la investigación participativa, se refiere al papel del investigador en su trato intensivo con las personas involucradas en el proceso de investigación, para entenderlas.

De la misma manera, la investigación fue apoyada en un diseño de campo puesto que la información es obtenida en el lugar donde se desarrolla los hechos, muchos de los conocimientos adquiridos son gracias a la integración directa con el entorno de trabajo, directivos, docentes, obreros y personal administrativo. La información obtenida en este medio se considera como datos primarios. Asimismo, la investigación se desarrolló en 4 fases (Diagnostico, planificación, ejecución y evaluación de la propuesta).

En tal sentido, se utilizó como técnica de recolección de información la entrevista y la observación participante; puesto que la misma, tiene una actitud abierta, libre de juicios, estar interesado en aprender más acerca de los otros, ser consciente de la propensión a sentir un choque cultural y cometer errores, la mayoría de los cuales pueden ser superados, ser un observador cuidadoso y tener buena escucha, y ser abierto a las cosas inesperadas de lo que se está aprendiendo. 
En ese orden de ideas, para darle respuesta al guion de entrevista se utilizaron como informantes clave a 3 docentes de la Escuela Bolivariana José Vicente Unda. Igualmente, analizar la información proporcionada por los informantes claves se utilizó el proceso de categorización; puesto que el mismo es un proceso que minimiza la información, el cual consiste en la segmentación de elementos singulares, o unidades, que resultan relevantes y significativas desde el punto de vista de nuestro interés investigativo.

De la misma forma, para el análisis de la información se utilizó la técnica de triangulación de datos, la cual es una de las técnicas de análisis de datos más características de la metodología cualitativa. En tal sentido, la triangulación de datos utiliza una variedad de datos para realizar el estudio, provenientes de diferentes fuentes de información, donde implicara compararcontrastar la consistencia de la información derivada de la observación y la entrevista en profundidad.

Al respecto, para realizar el proceso de triangulación en la presente investigación, se utilizará la opinión emitida por los informantes claves, el aporte de una fuente bibliográfica y la interpretación del investigador.

\section{Consideraciones Finales}

Entre las consideraciones finales se estima que el poco conocimiento en producción de abono orgánico con microorganismos eficientes que poseen los docentes de la escuela Bolivariana José Vicente Unda, ocasiona que los mismos, no se involucren en los programas de abordaje de los aspectos relacionados con la agricultura ecológica.

De la misma manera, la creación de actividades prácticas a través del plan acción para la producción de abono orgánico mediante microorganismos eficientes representa un aporte de suma importancia para el fortalecimiento de los espacios socioproductivos en la institución, manteniendo la biodiversidad y disminuyendo el impacto negativo al ambiente. 


\section{Referencias}

APNAN (2003). Manual de Aplicación. Japón: Red de Agricultura natural de para la Región Asia/Pacifico.

Biosca, A. (2001). ¿Qué son microorganismos eficientes? Quito, Ecuador: s.e.

EARTH (2008). Tecnología EM. EMRO. Effective Microorganismo Research Organization, Inc. Limon, Costa Rica.

Gómez, D. (2012). Plan de Gestión de calidad en el Proyecto Aporte la Flor del Proyecto Hidroeléctrico Toro 3 utilizando la guía PMI. Proyecto final. Costa Rica: Instituto Tecnológico de Costa Rica.

Gómez, J. (2000). Abonos orgánicos. Colombia: Impresora Feriva, S.A. Hurtado, L. (2001). Microorganismos eficientes. Japón: Proyecto FUNDASES.

Martínez, S. (1999). Experiencias con Microorganismos Eficientes. Caracas: Medecar.

Monasterio, R. (2008). Suelos Productivos. Caracas: Remir.

Piedrabuena, M. (2003). Agricultura Ecológica. Lima: LAMEDA.

Rodríguez, M. (2010). Agricultura Sostenible. Caracas: Medecar.

Zérega, L. (1993). Manejo y uso agronómico de la cachaza en suelos cañameleros. Caña de Azúcar. 11(2): 71-92. Venezuela. 


\section{Diana Carolina Cuevas Ordoñez}

e-mail: diana cuevas01@hotmail.com

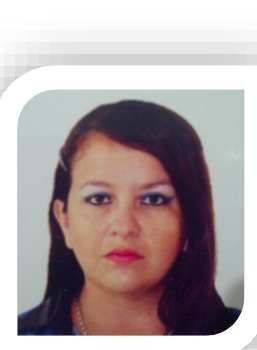

Nacida en Barinitas, municipio Bolívar, estado Barinas, Venezuela. El 07 de Mayo de 1985. Es Licenciada en Educación mención Integral egresada de la Universidad Experimental de los Llanos Ezequiel Zamora (UNELLEZ 2007). Se desempeña como docente de Aula en función de Coordinadora del Programa Todos Manos a la Siembra (PTMS), en la Escuela Nacional Bolivariana "José Vicente Unda". Actualmente es maestrante en Educación, Ambiente y Desarrollo en la UPEL, Núcleo Académico Barinas, donde trabaja en el desarrollo de esta investigación denominada plan para la Producción de Abono Orgánico mediante Microorganismos Eficientes.

El contenido de este manuscrito se difunde bajo una Licencia de Creative Commons ReconocimientoNoComercial-Compartirlgual 4.0 Internacional 